\title{
Financial Management Practices and Growth of Public Hospitals in Nyeri County, Kenya
}

\author{
Beatrice Wairimu Muturi' ${ }^{1}$, Dr Mungai John² \\ ${ }^{1}$ School of Business, Kenyatta University, Kenya \\ ${ }^{2}$ Department of Accounting and Finance, School of Business, Kenyatta University, Kenya
}

\section{ABSTRACT}

The provision of health care is among the social pillars in the vision 2030. The health sector has been characterized by many challenges ranging from recent strikes by health workers, poaching of workers by private hospitals and health workers looking for greener pastures outside the country because of poor management of the sector and poor infrastructure. Despite the support from the government, public hospitals in Nyeri County are straining to meet their financial obligations. Challenges ranging from inability to meet daily expenses, delayed payment of workers, delayed national government reimbursements and diminishing patient's expectations. The objectives of the study were to investigate how budgeting, internal control systems, financial tracking, and waiver affect financial management practices and growth in government hospitals. The management and movement of funds as aligned to the budget is critical for a public hospital's growth. But experience and exposure in finance management reveal that the financial management processes of public hospitals are generally weak and dominated by conditions of resource scarcity vis-a-vis the ever-increasing agenda of development activities on which such funds could be spent. The study used a descriptive survey design. The study targeted 202 respondents who were the employees of the four county public hospitals under study. Stratified simple random sampling was used, and a sample of 101 respondents was selected. The study used both primary and secondary data sources for data collection. Data was analyzed by the aid of the Statistical Package for Social Studies (SPSS) computer software through frequencies, means, percentages, correlation coefficient as well as regression method. Tables and graphs were used for data presentation. The findings indicated that there has been an increase in the number of operational cost in majority of the hospitals. Majority of the public hospitals experience a lot of challenges and delays before budget is approved. The findings indicated that there are several steps that should be followed before authorization of any payment in hospital. The results presented poor control of revenue in the hospital and lack of proper coordination and monitoring. The study findings indicate that financial tracking procedures are hard to follow and that the procedures are not very clear to all the employees. Majority of the respondents argued that there is lack of management support when it comes to financial tracking in the public hospitals in Nyeri County. The relationship between audit practices and growth of public hospitals is strong and positive and the relationship between financial tracking and growth of public hospitals is weak negative and significant. The study concludes that the relationship between audit practices and growth of public hospital was positive and significant and that a positive change in audit practices would result to a positive change in the growth of public hospitals. The study recommended that sufficient funds to the public hospitals should be disbursed early enough to enable proper planning and budgeting. The study also recommended that employees working in the public hospitals in Nyeri County should consider financial tracking as a daily task and that there is need for the County officials to be trained on the audit requirements and audit procedures.

Key Words: Financial Management Practices, Budgeting Process, Audit Practices, Financial Tracking

DOI: DOI 10.35942/ijcfa.v2i3.143 
International Journal of Current Aspects in Finance, Banking and Accounting, Volume 2, Issue 3, 2020 PP 1-13, ISSN 2707-8035

[IJCAB

Cite this Article:

Muturi, B., \& Mungai, J. (2020). Financial Management Practices and Growth of Public Hospitals in Nyeri County, Kenya. International Journal of Current Aspects in Finance, Banking and Accounting, 2(3), 1-13. https://doi.org/10.35942/ijcfa.v2i3.143

\section{Introduction}

Financial management process of a non-profit making organization such as institutions of higher learning, hospitals is generally dominated by the scarcity of resources. These institutions face a lot of challenges, which include limited resources and opportunities for generating additional income but are faced with ever-increasing agenda activities that require fund to be spent (Booth, 2013). This is brought forth in the complexity theory which argues that unpredictable behavior or any complex functions can arise from simple deterministic functions. Intuitively, the resource allocation activities in collaboration with the management of these organizations have received relatively little attention in economic literature. Accountants and financial managers as individuals and as occupational groups are mostly invisible in the growing body of financial management literature (Lightbody, 2010). Financial management, therefore, does not play a major role in public, academic institutions' decision making.

According to Hansen and Werner felt (2009), there are two models of firm performance that provide determinants factors that impact the performance. The organizational model elaborates further about factors as organizational culture, human resources, organizational climate, and leadership styles. According to Chien, (2004), five factors determine organizational performance; organizational culture, human resource policies, leadership style and environment, job design and model of motive. The economic model, industry characteristics, quality of resources, and firm's position relative to its competitors are determinants of organizational performance. Public health is fundamental to $21^{\text {st }}$-century healthcare and shares the same overall goals as the rest of the health care system which include; minimizing premature deaths, reducing the effect of diseases, and disability, and injury (World Health Organization (WHO), 2003). Indeed millennium development goal (MDG) number 5 sought to achieve universal maternal health by 2015 (Booth, 2014). The primary intent of public health is to promote a healthier population. This is quite essential to a sustainable health care system, and also provides economic and social benefits for the country, due to increased productivity.

Spending in Healthcare is a crucial component in any country's industrialized economy. Healthcare provides sources of employment in rural areas especially to the people with highly skilled workers. The United States of America public spending accounts for nearly half of the 2009 health spending, while other countries like Switzerland account for 60\%, Norway, and the UK account for $84 \%$. Norway accounts for $\$ 4501$ per capita expenditure and which had higher spending costs in public health more than the United States of America, which had $\$ 3,795$. In the United States of America public per capita, spending exceeded countries like New Zealand, Australia, UK, Sweden, and even Japan in their per capita health spending. According to Whetten (2014), the services of health in Scotland Wales England North Ireland were all funded by UK taxpayers, but with the development of political Devolution in 1999, different policies government systems are being employed. The clubs in the financing have constrained the extension and improvement of health care delivery in part of Africa. Sub-Saharan Africa accounts for only $11 \%$ of the world's total population, but it records the highest global disease burden of 24\% (international finance corporation, 2017). It is alarming that the region commands less than $1 \%$ of the expenditure in the Globe related to health. According to Young (2010) in the continent of Africa, public sector funding on health 
International Journal of Current Aspects in Finance, Banking and Accounting, Volume 2, Issue 3, 2020 PP 1-13, ISSN 2707-8035

[IJCAB

care remains and even across the 52 countries. According to Schindler (2011), many African countries signed the Abuja declaration which pledged to divert $15 \%$ of their national budget to help, but the majority of the nations remain far from that target according to the recent estimates already seven countries have reduced their spending on health over the past few years. More than almost half of the cost in Healthcare on the continent of Africa is currently made out of the pocket of the common maintaining a ratio that rises to nearly $90 \%$ in some of the countries in Africa with many of the patients unable to afford some of the significant treatment thus forcing the costs to be kept Low by the inability of people to pay.

In Kenya health care sector highly depends on out of the pocket payments. According to Chuma and Okungu (2011), government funds are only availed through the historical incremental approach. The healthcare sector is massively underfunded in Kenya and contributes to the failure in other sectors. The low income earners add a more substantial proportion of their income to the Healthcare sector than the rich. The need for healthcare sector financing in Kenya is alarming, and there are immense risks related to the supply of healthcare in Kenya. There is little progress that has been made by the country in terms of achieving the international benchmarks, which include the Abuja target of $15 \%$ government budget. Tumor and Ukungu 2011 argued that the Kenyan health system is profoundly Latin policies that aim at promoting equity and enabling equitable distribution of resources related to health care and also lack of policy addressing the needs of the Venerable poor and the needy in the society. However, there are some of the challenges that have been addressed by the government through the universal coverage Healthcare, but the government is yet to adopt a systematic approach to health care financing. The Kenyan health system has failed to recognize the policies of promoting equity and addressing the needs of the vulnerable and poor in the society by progressing and recognizing the need to put them in the challenges relating to Healthcare (Chuma \& Okungu, 2011). There are some of the progress which has been made in addressing the Equity challenges that involve universal health coverage, which has received considerable support in the rural areas. The Approach has focused on the broader health Systems by ensuring that there is efficiency and equity in the health system.

Measuring organizational performance is the first step in improving performance in the health sector. Progress in the process of quantification of its effects which will stimulate a positive result. The management in all industries should be aware that all the measures that they use may be harmful or may bring negative consequences if they are misused in the wrong situations. Therefore it is recommendable to the government to make sure that they study the environment before the use of the application, the negative effect of adopting performance measures (GoK, 2004). The public hospital growth is well-defined depending on either clinical or administrative functions or the set target (Flint, 2000). The ultimate goal of any Healthcare is to better the health of the majority of patients of people living in that area, but there are many intermediate measures and outcomes and processes. The target of this Healthcare may relate to traditional functions of hospitals such as treatment, diagnosis, rehabilitation care as well as research and teaching. So many hospitals are changing, and the emphases are now shifting from inpatient care to ambulatory care, Healthcare networks, and community outreach programs. The function of hospitals may thus be expected to include the elements of public health community care as well as employment function and social needs. Nyeri County hospitals have experienced divergent challenges in financial management practices and Growth, ranging from budgeting to internal control systems (Manyani, 2011). The growth of Hospitals will be measured through the availability of facilities and hospital service delivery to the County. 
International Journal of Current Aspects in Finance, Banking and Accounting, Volume 2, Issue 3, 2020 PP 1-13, ISSN 2707-8035

[IJCAB

\section{Statement of the Problem}

Despite the support from the government, public hospitals in Nyeri County are straining to meet their financial obligations due to dwindling budget provisions. Challenges ranging from inability to meet daily expenses, increased costs of operations, delayed payment of workers, delayed national government reimbursements, and diminishing patient's expectations. These have resulted in dwindling service delivery in public hospitals in Nyeri County (Waddell, 2014). Despite the significant contribution of public hospitals in Kenya through their growth, the support by the government through the allocation of funds and availing the relevant facilities are not sufficient to support the ever-increasing Kenyan population. Oladipo (2011) studied the impact of the elaborative financial management system on the performance of public hospitals in Africa. The study found that hospitals are improving, but there are still cases of weak commercial policies and procedures. The study found that unlike their profit counterparts, whose system of accounting showcases the results of economic activities, hence, giving a clear outline on how the the objective has been achieved; public hospitals are mostly associated with expanding and raising the resources according to particular budget plans. The study presented a methodological gap in that it described the situation under the public hospital in Africa through such an approach as descriptive research design. The current study will fill the gap by using both inferential and descriptive statistics. The study's scope was broad since it focused on Africa, while the present study will focus on public hospitals in Kenya. Therefore, this study looked into establishment of the Growth and financial management practices of Public Hospitals in Nyeri County, Kenya.

\section{The objectives of the study}

The general objective was to investigate the effect of financial management practices on financial growth of Public Hospitals within Nyeri County, Kenya.

Specific objectives of this study were:

i. To determine the effect of budgeting process on financial growth in public hospitals in Nyeri County.

ii. To establish the effect of audit practices on financial growth in public hospitals in Nyeri County.

iii. To examine the effects of financial tracking on financial growth in public hospitals in Nyeri County.

\section{Theoretical framework}

The study will be guided by the following theories: Budget theory, goal setting theory, contingency theory, and Stakeholder Theory.

\subsection{Budget Theory}

The budget theory was proposed by Henry Adams, William Willoughby, in 1978. Budgeting theory is the study of social and political motivation behind the civil society and the government budgeting. According to Rhee (2009), proper budgeting is a critical success factor despite the fact that it is a painful process that takes much effort and time. The author proposed that there are two significant factors that influence budget process, which are the availability of the external resources and level of revenues collected. External Resources bridge the gap that arises from the revenue shortfall, in the event that, the revenues fall short of the projected level. This affects the implementation of the budget to the extent that, expenditures must be reduced either by cutting short the operational or capital projections, hence affecting the service delivery (Heller, 2005). External resources such as grants and loans are included in the budget 
International Journal of Current Aspects in Finance, Banking and Accounting, Volume 2, Issue 3, 2020 PP 1-13, ISSN 2707-8035

[IJCAB

in line with the commitment by the donors though they pass through the Integrated Financial Management and Information System (IFMIS) also bring shortfall if not honored.

According to Rhee (2009), public budgeting can be approached through a lens of two theoretical perspectives; that is descriptive and normative. A normative theory (or a welfare function or a hierarchy of values) of budgeting is a comprehensive and specific political theory detailing what the government's action ought to be at a particular time. It specifies a method for maximizing returns for budgetary expenditures. Given that the budget represents the outcome of political struggle, a normative theory of budgeting suggests the elimination of any such conflict over the government's role in society. It attempts to recommend solutions based on values rather than describing observations. Advice is based on a much narrower range of observations than descriptive theory, and its proposed solutions may be based on values rather than observation. This theory is applicable in this study, for it supports the budgeting process.

\subsection{Goal-setting Theory}

Locke and Latham (2002) developed a goal-setting Theory. The theory was established within the industrial organization in psychology over the last 25 years based on 400 field and laboratory studies. The study proposed that specific goals that lead to task growth are easy goals that are the best in the organization. Budget is a way of putting the organization on toes to achieving certain goals within a set time limit. The main goals that lead to higher growth when people dedicate their time to "do their best"'(Locke\& Lotham 1990) and this seeks to ensure that there is improvement and growth that will help to have specific challenging goals being demonstrated in hundreds of laboratory and field studies (Locke \& Latham, 2002). These goals help both the organization and individuals to grow to achieve the set goals in the longterm. Goals help in providing directions and our standards of organs, whose progress can be monitored by progress in achieving the challenging goals hence enabling employees to be guided and have their growth refined. The practitioner and scholarly literature that contributes significantly in specifying the task that can boost the growth and motivation of employees. The specific goals aimed at increasing the efforts of individuals that face setbacks and develop new strategies in the commitment of organization goals. These theories applicable in this study seem he supports budgets in hospitals. We should be set in a manner that employees feel the achievement is being challenged by primarily achieving the state budget rules, which helps in motivating them to make the targets. When setting high goals within an organization, it is crucial to have efficiency or personal effectiveness which helps in self-satisfaction and positively affect the sense of well-being especially when the goals are being conquered, considering challenging many employees within the organization will positively impact the sense by which employees overcome the recognized challenges.

\subsection{The Contingency Theory}

Fred Edward Fiedler developed contingency theory in 1966. It proposes that the organization may not have the best way to be lead in an attempt to make the proper decision. The theory proposed that the optimal course of action is dependent upon external and internal situations. Contingency is an approach to the study of organizational behavior which tries to explain or give the condition factors such as culture, external environment and technology that influences organization functions and their design. The assumption which underlies contingency Theory is that there is no any form of organization structure that is uniformly applicable to all organizations. The effectiveness of the organization is dependent on the fit or the match between the kind of volatility in the environment, technology, organization size, the organization structure features, and its information systems (Woods, 2009). Contingency 
International Journal of Current Aspects in Finance, Banking and Accounting, Volume 2, Issue 3, 2020 PP 1-13, ISSN 2707-8035

[ICAB

Theory is usually used to describe the relationship that exists between the structure and context of the internal control systems, organizational growth, and financial tracking.

According to Cadez and Guilding (2008), internal auditors are specialists in the internal audit that have the ability to achieve the internal control effectiveness through the analysis, which will benefit the organization's effectiveness through internal control mechanisms efficiency. Cadez and Guilding (2008) identified some factors which may impact the management control systems, which are the technology, the size of the organization, the structure and the external effects, strategy, and Culture ;suggested that the Demons that are imposed by the technical task in any organization helps in the development of policy that will coordinate and control the internal entities of information technology and the environment as an essential and significant influence on the structure of the organization. During the implementation, uncertain conditions or atmosphere in routine transactions or technology and information are frequently internal. They argued that the dimensions of control and structure of authority increase the activities, structures, rules, and procedures that determine the description of individuals. In a contingency model, decentralized authority in the county government should be appropriate where an uncertain environment or no routine activities exists. Centralized authority is more encouraged when the situation is certain. The idea behind contingency Theory is the selection and use of control systems in the management in a way that the internal and external factors are being controlled (Fisher 1998). This establishes it clearly that factors such as structure, the size of the organization, environment strategy and the culture impacts the management control system. The theory will suggest that the demands imposed by the technical capacity in an organization will encourage the development of specific strategies that will help in coordination and control of internal activities (Daft, 2012). The theory is applied in this study to support the utilization of financial tracking, audit practices and budgeting processes to achieve significant growth in public hospitals.

\subsection{Stakeholder Theory}

According to this theory, firms have both stock and stakeholders who play different roles (Donaldson \& Preston, 1995). In other words, this theory argues that firms have obligations toward these members in the form of owners, shareholders, or equity holders through its growth and meeting their expectations. This function has seemingly been taken over by the view that the welfare of the organization should consider other significant stakeholders. As the name suggests, stakeholders have different shares of the stake in the organization. These individuals include the state or government, lenders, clients, employees, and suppliers. However, this definition is limited to a particular group where the organization is dependent on its survival.

Meek and Gray (1988) argued that the consensus that develops from the perception that accounting for profit is the sole measure of return on equity only takes into consideration the return of the shareholder. However, it is noteworthy that the added value and growth is the most effective determinant that is created by stakeholders; it is also available to the same stakeholders. Typically, this value and growth arise through the wealth that is produced by the sufficient use of the organization's resources before the actual allocation is carried out among bondholders, shareholders, the state and workers. According to Belkaoui (2002), stakeholders' perception regarding an entity requires the involvement of value-added as an instrument of the created total wealth to determine the growth incurred and created in favor of all stakeholders. This theory supports the growth of public hospitals as a means of increasing stakeholder's wealth. 
International Journal of Current Aspects in Finance, Banking and Accounting, Volume 2, Issue 3, 2020 PP 1-13, ISSN 2707-8035

通CAB

\section{Conceptual Framework}

This concept illustrates the relationship between independent and dependent variables. The independent variables were budgeting, internal controls, financial tracking and waivers whereas the dependent variable is the growth of public hospitals.

\section{Independent variables}

\section{Dependent variable}

\section{Budgeting Process}

-Type of Operational costs

- Budget participation

- Number of Stages/processes

\section{Audit Practices}

- Audit Controls

- Number of Internal audits

- Policy follow up on Audit

\section{Financial Tracking}

-Number of times in a year

-Number of the Reports tracked

-Tracking Procedures

\section{Figure 1 Conceptual Framework}

\section{Source: Researcher (2019)}

\section{Research Methodology}

The researcher used the descriptive research design. The importance of this type of research is to determine means, incidences, and other statistical data of the population. With this information, the researcher was able to decide on the trends and additional information about the population. The targeted population comprised 202 employees in the public hospitals in Nyeri County which were made up of 80 Administration staff, 38 Finance and Accounts staff, and Social health workers totaling to 84 .

The use of questionnaires collected primary data. A questionnaire is defined as a research parameter that comprises of a series of questions and other prompts to gather information from respondents (Mugenda \& Mugenda, 2003). The researcher engaged the use of questionnaires that optimally use a structured questionnaire. The researcher engaged research assistants who trained to undertake data collection. The questionnaires were self-administered; hence, the researcher dropped them to the respondent, gave them time to complete, and then picked the 
International Journal of Current Aspects in Finance, Banking and Accounting, Volume 2, Issue 3, 2020 PP 1-13, ISSN 2707-8035

\section{[IJCAB}

questionnaire at a later date. The researcher also used closed and open-ended questions which allowed the collection of qualitative data. The data collection enabled ease of data as well as save time and allow for un-ambiguity in answering questions and thus a thorough study.

After data collection, data was checked for consistency. According to (Jewell, 2011) data needs to be analyzed and presented in a way that communicates the information and enables accurate conclusions to be drawn. The method used to analyze the data was panel data analysis to understand the relationship between the variables. The quantitative data was analyzed using simple descriptive statistics including percentages. This was done with the help of the Statistical Package for Social Sciences (SPSS) version 24. Since the study involves an in-depth analysis of opinion content analysis was also used. The analyzed data was presented using frequency tables and figures. A a multiple regression model was adopted. Therefore, the growth of the hospital was expressed as a function of the budgeting process, audit practices, and financial tracking.

\section{Data Analysis Results}

The study sought to establish the inferential statistics related to the study variables. The sections below presents the findings on correlation coefficients, analysis of variance model summary and regression coefficients.

Table 1 Correlation Analysis

Correlations

\begin{tabular}{|c|c|c|c|c|c|}
\hline & & Budgeting Process & Audit Practices & $\begin{array}{l}\text { Financial } \\
\text { Tracking }\end{array}$ & $\begin{array}{l}\text { Public Hospital } \\
\text { Growth }\end{array}$ \\
\hline \multirow{4}{*}{ Budgeting Process } & $\begin{array}{l}\text { Pearson } \\
\text { Correlation }\end{array}$ & 1 & & & \\
\hline & Sig. (2-tailed) & & & & \\
\hline & $\mathrm{N}$ & 82 & & & \\
\hline & $\begin{array}{l}\text { Pearson } \\
\text { Correlation }\end{array}$ & -.013 & 1 & & \\
\hline \multirow[t]{3}{*}{ Audit Practices } & Sig. (2-tailed) & .910 & & & \\
\hline & $\mathrm{N}$ & 82 & 82 & & \\
\hline & $\begin{array}{l}\text { Pearson } \\
\text { Correlation }\end{array}$ & -.122 & .018 & 1 & \\
\hline \multirow[t]{3}{*}{ Financial Tracking } & Sig. (2-tailed) & .276 & .871 & & \\
\hline & $\mathrm{N}$ & 82 & 82 & 82 & \\
\hline & $\begin{array}{l}\text { Pearson } \\
\text { Correlation }\end{array}$ & -.321 & .842 & -.141 & 1 \\
\hline \multirow[t]{2}{*}{ Public Hospital Growth } & Sig. (2-tailed) & .001 & .006 & .007 & \\
\hline & $\mathrm{N}$ & 82 & 82 & 82 & 82 \\
\hline
\end{tabular}

Source: Research Data (2020)

The findings in Table 1 indicates that there was a very weak and insignificant correlation amongst the Independent variables ( budgeting process audit practices and financial tracking) is indicated by correlation coefficients which are less than 0.3 and $\mathrm{P}$ - value greater than 0.05 . The correlation between budgeting process and growth of public hospitals was weak and negative as indicated by a Pearson correlation of -0.321 . The correlation between audit practices and growth of public hospitals in Nyeri County was strong and positive as indicated by a Pearson correlation coefficient of 0.842 . A correlation coefficient of -0.141 indicates that 
International Journal of Current Aspects in Finance, Banking and Accounting, Volume 2, Issue 3, 2020 PP 1-13, ISSN 2707-8035

\section{[IJCAB}

the relationship between financial tracking and growth of public hospitals in Nyeri County was weak negative and significant.

The model summary presents the coefficients of correlation $(\mathrm{R})$ and coefficients determination ( $\mathrm{R}$ squared). The coefficient of correlation $(\mathrm{R})$ presents the nature and the strength of relationship between variables when the coefficient of determination presents the extent to which the independent variables (budgeting process, audit practices and financial tracking) predicts the changes in the dependent variable (growth of public hospitals).

Table 2 Model Summary

\begin{tabular}{|l|r|r|r|r|}
\hline Model & \multicolumn{1}{|c|}{ R } & R Square & Adjusted R Square & Std. Error of the Estimate \\
\hline 1 & $.403^{\mathrm{a}}$ & .341 & .204 & 1.93828 \\
\hline
\end{tabular}

a. Predictors: (Constant), Financial Tracking, Audit Practices, Budgeting Process

\section{Source: Research Data (2020)}

The findings in table 2 to indicate that there was a weak positive correlation between financial tracking, audit practices, budgeting process and growth of public hospitals in Nyeri County $(\mathrm{R}=0.403)$. The adjusted $\mathrm{r}$-squared of 0.204 indicates that $20.4 \%$ changes in the growth of public hospitals in Nyeri County was determined by financial tracking, audit practices and budgeting process. $79.6 \%(100-20.4)$ changes in the growth of public hospitals in Nyeri County was determined by other factors not considered in this model.

\section{Table 3 Analysis of Variance}

\begin{tabular}{|rr|r|r|r|r|r|}
\hline \multicolumn{1}{|c|}{ MNOdel $^{2}$} & Sum of Squares & df & Mean Square & F & Sig. \\
\hline \multirow{2}{*}{1} & Regression & 12.569 & 3 & 4.190 & 1.115 & $.008^{\mathrm{b}}$ \\
& Residual & 293.040 & 78 & 3.757 & & \\
& & 305.610 & 81 & & & \\
\hline
\end{tabular}

a. Dependent Variable: Public Hospital Growth

b. Predictors: (Constant), Financial Tracking, Audit Practices, Budgeting Process

The findings in table 3 presents that the model was significant $(\mathrm{P}=.008)$ at $5 \%$ significance level in explaining the relationship between growth of public hospitals and changes in financial tracking audit practices and budgeting process. The findings indicate that at least one of the variables considered (financial tracking, audit practices, budgeting process) can be used to predict the changes in the growth of public hospitals in Nyeri County. Regression coefficients as presented by the B column in table 4 indicate the changes in number of units of growth of public hospitals as a result of changes in the predictor variables. A negative coefficient indicates that the variables move in the opposite direction while the positive coefficient indicates that the variables move in the same direction. The significant value ( $\mathrm{P}$ value) indicates whether the changes in the predictor variable were vital in explaining the changes in the predicted variables. 
International Journal of Current Aspects in Finance, Banking and Accounting, Volume 2, Issue 3, 2020 PP 1-13, ISSN 2707-8035

[IJCAB

\section{Table 4 Regression Coefficients}

\begin{tabular}{|c|c|c|c|c|c|c|}
\hline \multicolumn{7}{|c|}{ Coefficients $^{\mathbf{a}}$} \\
\hline \multirow[t]{2}{*}{ Mo } & & \multicolumn{2}{|c|}{ Unstandardized Coefficients } & \multirow{2}{*}{$\begin{array}{c}\begin{array}{c}\text { Standardized } \\
\text { Coefficients }\end{array} \\
\text { Beta }\end{array}$} & \multirow[t]{2}{*}{$\mathrm{T}$} & \multirow[t]{2}{*}{ Sig. } \\
\hline & & $\mathrm{B}$ & Std. Error & & & \\
\hline & (Constant) & 24.364 & 3.180 & & 7.662 & .000 \\
\hline & Budgeting Process & -.157 & .126 & -.140 & -1.253 & .000 \\
\hline & Audit Practices & .843 & 1.109 & .843 & 1.392 & .001 \\
\hline & Financial Tracking & -.051 & .036 & -.159 & -1.419 & .010 \\
\hline
\end{tabular}

a. Dependent Variable: Public Hospital Growth

The findings in table 4 presents that the constant was 24.364 units indicating that when budgeting process, audit practices and financial tracking were held constant, the growth in public hospital was 24.364 units. The adopted model in the study was $\mathbf{Y}=\mathbf{2 4 . 3 6 4}+\mathbf{- 0 . 1 5 7 X _ { 1 }}$ $+\mathbf{0 . 8 4 3 X _ { 2 }}+\mathbf{- 0 . 0 5 1 X _ { 3 }}+\mathbf{c}$. The interpretation of the model is presented in the subsequent paragraphs. The findings in table 4 indicates that relationship between budgeting process and growth of public Hospital was negative and significant $(\mathrm{B} 1=-.157, \mathrm{P}=0.000)$. The results also indicate that one unit change in the budgeting process would result to -0.157 units changes in the growth of public hospitals. The results indicate that budgeting process positive change would result to the negative changes in the growth of public Hospital. Melek (2014) carried out a study relating to the impact of participation in budgeting on managerial growth through step by step commitment of the organization. The regression results disagreed with the current findings in that there was positive and significant impact of budgeting participation on corporate commitment through managerial performance.

The findings in table 4 indicates that the relationship between audit practices and growth of public hospital was positive and significant $(\mathrm{B}=.843, \mathrm{P}=.001)$. This indicates that a positive change in audit practices will result to a positive change in the growth of public hospitals. The study also indicates that one unit change in the Audit practices would result to 0.843 units changes in the audit practices. The findings are supported by Njenga (2013) who sought to estimate efficiency levels, factor of productivity growth, in public hospitals. The study found that there was positive and significant relationship between audit practices and growth in public hospitals. Results in the table 4 indicate that the relationship between financial tracking and the growth of public hospital was negative and significant. A positive unit change in financial tracking would result to the negative change in the growth of public hospitals. A unit change and financial tracking would result to -0.051 units changes in the growth of public Hospital. Obonyo (2011) findings disagrees on assessed the effectiveness of exemptions in enhancing access to health care services among the poor and vulnerable groups at Kenyatta National Hospital. The study found that financial tracking is positively correlated to performance of Kenyatta National Hospital.

\section{Conclusions}

Based on the summarized results on the effect of budgeting process on growth of public hospitals, the study concludes that the relationship between budgeting process and growth of public hospitals is weak and negative and that budgeting process positive change would result to the negative changes in the growth of public Hospital. Based on the summarized results on the effect of audit practices on growth of public hospitals, the study concluded that the relationship between audit practices and growth of public hospitals is strong and positive and 
International Journal of Current Aspects in Finance, Banking and Accounting, Volume 2, Issue 3, 2020 PP 1-13, ISSN 2707-8035

\section{[IJCAB}

that a positive change in audit practices would result to a positive change in the growth of public hospitals. Based on the study findings, the study concluded that the relationship between financial tracking and growth of public hospitals was weak negative and significant and therefore, a positive unit change in financial tracking would result to the negative change in the growth of public hospitals. The study made a conclusion that among the three variables considered (budgeting process, audit practices and financial tracking) only audit practices contributed to the positive changes in the growth of public hospitals.

\section{Recommendations}

Based on the study conclusions, the study recommended that sufficient funds to the public hospitals should be disbursed early enough to enable proper planning and budgeting. The study recommends that budget process should consider the needs of each public hospital and the patient capacity levels. The study recommended that employees working in the public hospitals in Nyeri County should consider financial tracking as a daily task and important in ensuring that transparency and accountability is maintained in all financial records. Financial tracking should be automated to save on costs and ensure accuracy. Based on the conclusions regarding the positive effects of audit practices, the study recommended that the frequency and the number of audit practices should be increased since the increase will result to positive changes in the growth of public hospitals. There is need for the County officials to be trained on the audit requirements and audit procedures. Employees should be sensitized on the importance of keeping proper and time records in the County governments.

\section{References}

Ahmed I. H., Babar Z. B. and Kashif, R. (2010). Financial Management Practices and Their Impact on Organizational Performance. World Applied Sciences Journal, Vol. 9, No. 9, pp. 997-1002.

Allison, M., and Kaye, J. (2015). Strategic Planning for Nonprofit Organizations: A Practical Guide and Workbook, John Wiley and Sons

Amit, C. (2013). Innovating Growth through Six Sigma. A strategic approach for combining Robustness with Flexibility. Available at Http: //www. findarticies.BCom (Accessed 25 Sept. 2005)

Anthony, R., and Young, D. (1994). Management Control in Not-for-profit organizations, Boston: Richard D. Irwin, Inc.

Barney, J. B., 2012. Gaining and sustaining competitive advantage (2nd ed.). UpperSaddle River, NJ: Pearson Education, Inc.

Blazek, J. (2006). Financial Planning for Not-for-profit Organizations, New York: JohnWiley\& Sons, Inc.

Booth, P. (2013). Accounting and Accountants in Organizational context: A case study of Voluntary Organization. Unpublished Ph.D. Thesis, Griffith University

Booth, P. (2014). Accounting and Accountants in Organizational context: A case study of Voluntary Organization. Unpublished Ph.D. Thesis, Griffith University

Burke, J.C., Modarresi, S. (2010). To keep or not to keep performance funding? Signals from stakeholders, The Journal of Higher Education, Vol. 71 No.4, pp.432-53.

Burns, J., Fraser, R.W. (2010). Conceptualizing Management Accounting Change: AnInstitutional Framework, Management Accounting Research, Vol. 11 Pp.3-25

Cameron, K. S., and Whetten, D. A. (2011). Perceptions of organization effectiveness across organization life cycles. Administrative Science Quarterly, 26: 525-544.

Camisón, C. (2005). On how to measure managerial and organizational capabilities.Multi-item models for measuring distinctive competences, ManagementResearch, Vol. 3 No.1, pp. $27-48$ 
International Journal of Current Aspects in Finance, Banking and Accounting, Volume 2, Issue 3, 2020 PP 1-13, ISSN 2707-8035

[IJCAB

Chen, S., and Dodd, J. L., 2001. Operating income, residual income, and EVATM: Whichmetric is more value relevant? Journal of Managerial Issues, XIII(1). 65-86.

Cooper, D., and Schinder, P. (2013). Business Research Methods (8th Ed.). New Delhi: Tata Mcgraw Hill.

Cox, J. C., and Morgan, M. (2014). Option pricing: A simplified approach. Journal of Financial Economics, 7: 229-263.

Dorothy, A. (2009). Financial Management, Center for Philanthropy and Nonprofit Leadership

Earl, N. (2000). How planning and capital budgeting improve SME performance. LongRange Plan, 31(6). 848-856.

Ebrahim, A. (2005). Accountability myopia: Losing sight of organizational learning, Nonprofit and Voluntary Sector Quarterly, Vol. 34 No.1, pp.56-87.

Flint, D. (2002). True and Fair View in Company Accounts. London: The Institute of Chartered Accountants of Scotland: Gee and Co (Publishers) Limited.

Financial Management Act (2012), Management of Public Financial Resources in Kenya

Gitman, L. J. (2007). Principles of Managerial Finance. New York: Addison Wesley.

Gloy, B., and LaDue, E. (2003). Financial Management Practices and Farm Profitability. Agricultural Finance Review: 57-174.

Hoopes, D.G., Madsen, T.L., and Walker, G. (2003). Guest editors' introduction to the special issue: why is there a resource-based view? Toward a theory of competitive heterogeneity, Strategic Management Journal, Vol. 24 No.10, pp.889-902.

Kiel, D., and Elliott, E. (1996). Chaos Theory and Social Sciences. Ann Arbor: University of Michigan Press.

Lewis C. W., (2005). The Field of Public Budgeting and Financial Management, CRC Press, Mumbai

Lewis, V. B. (1952). Toward a Theory of Budgeting. Public Administration Review, 12(1) 4254

Lightbody, M. (2000). Financial Managers in a Church Organization. Understanding their Experience. Unpublished Ph.D. Thesis. University of Adelaide

Maseko N, Manyani O (2011). Accounting practices of SMEs in Zimbabwe: An investigative study of record-keeping for performance measurement (A case study o fBindura). Journal of Account and Tax, 3(8). 171- 181.

Mautz, R.K., and Sharaf, H.A. (2011). The Philosophy of Auditing. Sarasota, Florida: American Accounting Association

Mobegi, H. N. (2009). A survey of the extent of implementation of an integrated financial management information system (IFMIS) as a tool for sustainable financial management in government. Unpublished MBA Project, University of Nairobi.

Mugenda, A., and Mugenda, O. (2003). Readings in Research Methods: Quantitative and Qualitative Approaches. African Centre for Technology Studies, Nairobi, Kenya

Premchand A (2004). Government Budgeting and Expenditure Controls: Theory and Practice Published by International Monetary Fund

Shah, A. (2009). Budgeting and budgetary institutions. World Bank Publications.

Spira, LF, and Page (2003). Risk management: the reinvention of internal audit and the changing role of internal audit, Accounting, Auditing, and Accountability Journal, Vol. 16 No. 4 , pp. 640-61.

Srinivasan, U. (2000). Current Budgeting Practices in US Industry, Quorum Books, NewYork, NY, 
International Journal of Current Aspects in Finance, Banking and Accounting, Volume 2, Issue 3, 2020 PP 1-13, ISSN 2707-8035

[JCAB

Waddell, S. (2000). Complimentary Resources: the win-win rationale for partnerships with NGOs, in Bendell, J. (Eds), Terms for Endearment, Greenleaf Publishing, Sheffield, pp.193-206.

Wagacha, M. (2000). Review of Kenya's Budget and Fiscal Strategy: 2000/2001. Institute of Policy Analysis and Research, Nairobi.Institute of Policy Analysis and Research, Nairobi.

This is an open-access article published and distributed under the terms and conditions of the (c) (i) (5) States unless otherwise stated. Access, citation and distribution of this article is allowed with full recognition of the authors and the source. Authors seeking to publish with an Internationally Peer Reviewed Journals should consider https://www.ijcab.org/ by writing to the Editor at editor@ijcab.org or submitting online at https://journals.ijcab.org/journals/index.php. The articles must be quality and meet originality test.

IJCAB 